\title{
Understanding the Detection of Shiga Toxin Producing Escherichia Coli: Virulence Factors, Pathogenicity Islands or Serotypes?
}

\author{
Colello Rocío*, Etcheverría Analía Inés and Padola Nora Lía* \\ Centro de Investigación Veterinaria de Tandil (CIVETAN), Universidad Nacional del Centro de la Provincia de Buenos Aires, USA \\ Received: March 06, 2018; Published: March 19, 2018
}

*Corresponding author: Colello, Rocío, Centro de Investigación Veterinaria de Tandil (CIVETAN), CONICET, CICPBA, Facultad de Ciencias Veterinarias, Universidad Nacional del Centro de la Provincia de Buenos Aires, Laboratorio de Inmunoquímicay Biotecnología, Pinto 399 (7000), Tandil, Argentina, USA, Tel: 549249154323843; Email: rocioc@vet.unicen.edu.ar

\begin{abstract}
Shiga toxin-producing Escherichia coli (STEC) are important food borne pathogens that can cause severe disease in children by producing two toxins (Stx1 and Stx2). This bacteria harbor several additional virulence factorsand have been classified in different serotypes that have been used as screening for detection of STEC. Aa is not possible to define when a STEC strain is pathogenic, it is important incorporate the risk assessment.
\end{abstract}

Abbreviations: STEC: Shiga Toxin-producing Escherichia coli; HUS: Hemolytic Uremic Syndrome; LEE: Locus of Enterocyte Effacement; LAA: Locus of Adhesion and Auto Aggregation; FSIS: Food Safety and Inspection Service; HACCP: Hazard Analysis and Critical Control Points; EFSA: European Food Safety Authority

\section{Introduction}

Shiga toxin-producing Escherichia coli (STEC) are important food borne pathogens that can cause severe disease in children, including a life-threatening complication such as bloody diarrhea and hemolytic uremic syndrome (HUS) [1]. The damage is produced by Shigatoxins encoded by stx 1 and stx 2 genes carried by lysogenic phages that infect the bacteria [2]. STEC must intimately adhere to epithelial cells through adhesions for deliver toxins efficiently to host organism. Intiman, encoded by eae gene, is the best characterized adherence protein inducing a characteristic histopathological lesion defined as "attaching and effacing" (A/E). A pathogenicity island called the locus of enterocyte effacement (LEE) encodes proteins necessary for the formation of the $A / E$ lesion, including intimin [1]. The presence of both eae and stx genes has been associated with enhanced virulence [3]. Nevertheless, the presence of LEE is not essential for pathogenesis, considering that some LEE negative STEC have been associated with severe disease in humans.

The mechanism used by LEE negative STEC strains to adhere and colonize to epithelial cells is poorly understood, although the Protein Sea has been involved in the cells adherence [4]. In a recent study in STEC LEE negatives, Montero, Velasco [5] identified a member of the Heat-resistant agglutinin family and characterized this antigen named Hem agglutinin from Shiga toxin-producing E. coli (Hes). They show that hes and other genes such asiha, pagC, ag43 were integrated in each of the four modules present in the new Island named Locus of Adhesion and Auto aggregation (LAA) whose presence is associated with severe disease. They have proposed hes as a genetic marker of LAA. According to serotype, STEC is classified in 0157: H7, recognized as the most important serotype associated with human infection, and non-0157 serotypes such as 091, 0104, 0113, and others that have been involved in human disease [6]. For instance, in 2011, the Food Safety and Inspection Service (FSIS) of USDA declared the "Big Six" (026, 045, 0103, 0111, 0121, and 0145) as adulterants through a Federal Register Notice and announced plans to start the Hazard Analysis and Critical Control Points (HACCP) verification testing for raw beef trim and ground beef [7].

According to a European Food Safety Authority report (EFSA, 2009), the major serotypes or serogroups of concern are 0157:H7, 026, 0103, 0145, 0111, and 09 [8]. Under the new rules, any 
meat that contains these sero groups cannot be sold as raw products. Karmali, Mascarenhas [9] proposed to classify STEC into five seropathotypes, according to their reported frequencies in human illness. Seropathotype A (0157:H7/NM), seropathotype B (026:H11, 0103:H2, 0111: NM, 0121:H19, and 0145: NM), seropathotype C (091:H21 and 0113:H21), seropathotype D and E (multiple). But, Scheutz [10] argued that this classification should not be used because it associates serotype with illness instead of the virulence profile, and proposes a new classification of STEC: HUS-inducing and/or epidemic outbreak potential STEC, human diarrhea inducing STEC, and animal-associated STEC.

Cattle are the main reservoir of STEC but other ruminant species such as, sheep, goats, and deer also act as reservoirs, shedding these bacteria through their feces, maintaining these pathogens among cattle herds, contaminating the environment and derived foods [11]. For public health investigation of STEC infection, in clinical and/or food samples the presence of the stx genes should be screened by PCR. However, the detection of these genes without the corresponding strains isolation is considered a presumptive diagnosis [12]. Risk analysis of food category considering the habits of consumer groups and the geographical and temporal relationship with human and food strains is necessary to determine the microbiological criteria for each foodstuff [13]. Efforts for risk assessment and stringent monitoring system are necessary to give an insight into the real clinical implications of virulence genes, serotypes and new genetic markers allowing the classification of STEC strains more efficiently.

\section{References}

1. Paton JC, Paton AW (1998) Pathogenesis and diagnosis of Shiga toxinproducing Escherichia coli infections. Clinical microbiology reviews 11(3): 450-479.

2. Beutin L, Miko A, Krause G, Pries K, Haby S, et al. (2007) Identification of human-pathogenic strains of Shiga toxin-producing Escherichia coli from food by a combination of serotyping and molecular typing of Shiga toxin genes. Applied and environmental microbiology 73(15): 47694775 .

3. Mathusa EC, Chen Y, Enache E, Hontz L (2010) Non-0157 Shiga toxinproducing Escherichia coli in foods. Journal of food protection 73(9): 1721-1736.

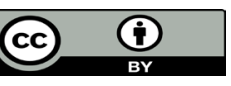

This work is licensed under Creative Commons Attribution 4.0 License

Submission Link: https://biomedres.us/submit-manuscript.php
4. Galli L, Miliwebsky E, Irino K, Leotta G, Rivas M (2010) Virulence profile comparison between LEE-negative Shiga toxin-producing Escherichia coli (STEC) strains isolated from cattle and humans. Veterinary microbiology 143(2-4): 307-313.

5. Montero DA, Velasco J, Del Canto F, Puente JL, Padola NL, et al. (2017) Locus of Adhesion and Autoaggregation (LAA), a pathogenicity island present in emerging Shiga Toxin-producing Escherichia coli strains. Scientific Reports 7(1): 7011.

6. Amézquita López BA, Quiñones B, Lee BG, Chaidez C (2014) Virulence profiling of Shiga toxin-producing Escherichia coli recovered from domestic farm animals in Northwestern Mexico. Frontiers in cellular and infection microbiology $4: 7$.

7. Yoon SC, William R Windham, Scott Ladely, Gerald W Heitschmidt, Kurt C Lawrence, et al. (2013) Differentiation of big-six non-0157 Shigatoxin producing Escherichia coli (STEC) on spread plates of mixed cultures using hyperspectral imaging. Journal of Food Measurement and Characterization 7(2): 47-59.

8. (2009) EFSA, Technical specifications for the monitoring and reporting of verotoxigenic Escherichia coli (VTEC) on animals and food (VTEC surveys on animals and food). The EFSA Journal 7: 1366.

9. Karmali MA, Mascarenhas M, Shen S, Ziebell K, Johnson S, et al. (2003) Association of genomic 0 island 122 of Escherichia coli EDL 933 with verocytotoxin-producing Escherichia coli seropathotypes that are linked to epidemic and/or serious disease. Journal of Clinical Microbiology 41(11): 4930-4940.

10. Scheutz F (2007) Experiences with non-0157 STEC and implications on public health programs. in Public Health Significance of Non-0157 Shiga Toxin-Producing Escherichia coli (STEC). Public Meeting, VA, Arlington, USA.

11. Etcheverría A (2016) Escherichia coli in Animals, in Escherichia coli in the Americas, Torres A (Edr.) Springer, Switzerland, USA, pp. 149-172.

12. Alonso MZ, Paula MA Lucchesi, Edgardo Mario Rodriguez, Nora Lía Padola (2012) Enteropathogenic (EPEC) and Shigatoxigenic Escherichia coli (STEC) in broiler chickens and derived products at different retail stores. Food Control 23(2): 351-355.

13. Victoria Brusa, Viviana Restovich, Lucía Galli, David Teitelbaum, Marcelo Signorini, et al. (2017) Isolation and characterization of non-0157 Shiga toxin-producing Escherichia coli from beef carcasses, cuts and trimmings of abattoirs in Argentina. PloS one 12(8): 0183248. 